\title{
Can the learning of laparoscopic skills be quantified by the measurements of skill parameters performed in a virtual reality simulator?
}

Natascha Silva Sandy, José Arnaldo Shiomi da Cruz, Carlo Camargo Passerotti, Hiep Nguyen, Sabrina Thalita dos Reis, Eder Maxwell Gouveia, Ricardo Jordao Duarte, Homero Bruschini, Miguel Srougi

Urology Department, University of Sao Paulo Medical School (NSS, JASC, CCP, EMG, RJD, HB, MS); Laboratory of Medical Investigation (LIM55), Urology Department, University of Sao Paulo Medical School (CCP, STR); Urology Department, Nove de Julho University (UNINOVE) (CCP), Sao Paulo, Brazil and Urology Department, Children's Hospital Boston (HN), Boston, Massachusetts, USA

\section{ABSTRACT}

Purpose: To ensure patient safety and surgical efficiency, much emphasis has been placed on the training of laparoscopic skills using virtual reality simulators. The purpose of this study was to determine whether laparoscopic skills can be objectively quantified by measuring specific skill parameters during training in a virtual reality surgical simulator (VRSS).

Materials and Methods: Ten medical students (with no laparoscopic experience) and ten urology residents (PGY3-5 with limited laparoscopic experience) were recruited to participate in a ten-week training course in basic laparoscopic skills (camera, cutting, peg transfer and clipping skills) on a VRSS. Data were collected from the training sessions. The time that individuals took to complete each task and the errors that they made were analyzed independently.

Results: The mean time that individuals took to complete tasks was significantly different between the groups ( $p<0.05)$, with the residents being faster than the medical students. The residents' group also completed the tasks with fewer errors. The majority of the subjects in both groups exhibited a significant improvement in their task completion time and error rate.

Conclusion: The findings in this study demonstrate that laparoscopic skills can be objectively measured in a VRSS based on quantified skill parameters, including the time spent to complete skill tasks and the associated error rate. We conclude that a VRSS is a feasible tool for training and assessing basic laparoscopic skills.

\section{ARTICLE INFO}

\section{Key words:}

Virtual Reality Exposure

Therapy; Education;

Laparoscopy

Int Braz J Urol. 2013; 39: 371-6

Submitted for publication:

February 27, 2012

Accepted after revision:

September 11, 2012

\section{INTRODUCTION}

Among the most important advances made in surgery in the last three decades, one of the most significant is the clinical introduction of minimally invasive interventions through laparoscopy and, more recently, robotic-assisted laparos- copic surgery. Initially restricted to a select few areas of surgery (1), the use of laparoscopy rapidly spread, necessitating capacitation as its use became adopted in many areas as the ideal form of surgical treatment.

The implementation of minimally invasive surgery requires specific and persistent training 
and is accompanied by a long learning curve (24). More psychomotor training and practice is required to perform laparoscopic interventions due to the two-dimensional representation of the surgical field through the monitors, the absence of orientation by digital touch, and the manipulation of structures by clamps and long work tools $(5,6)$. During the long learning process, the number and severity of intraoperative complications are often far greater than those observed in open surgery $(7,8)$. Thus, different clinical and laboratorial tools have been employed to combat this challenge, including the guidance of experienced mentors in patient interventions and training in animals or inanimate models $(9,10)$. This "ex-vivo" learning is viewed as particularly valuable because it eliminates the ethical constraint involved in teaching surgery in animal models or humans, is considered efficient in the acquisition of psychomotor skills, is secure, and has a reasonable cost (11). For these reasons, with the goal of improved patient safety and surgical efficiency, much emphasis has been placed on training laparoscopic skills using simulators that replicate the conditions encountered during actual surgeries.

The Surgical Council on Resident Education (SCORE), an agency dedicated to the development of training programs for surgical residents in the United States, has recommended the use of virtual reality surgical simulators in the laparoscopic training curriculum (12). However, it is not known if the use of these simulators results in a quantifiable improvement in laparoscopic surgical skills. The purpose of this study is to determine if laparoscopic skills can be objectively quantified by the specific skill parameters measured when performing in a virtual reality laparoscopic simulator.

\section{MATERIALS AND METHODS}

This prospective study was developed in the Laboratory of Experimental Minimally Invasive Surgery, Faculty of Medicine, University of Sao Paulo. The virtual reality surgical simulator "LapVR $^{\mathrm{TM}}$ ” (Immersion Medical, San Jose, California, USA) was used for a ten-week training program (one session per week). Ten medical students (from the $1^{\text {st }}$ through $4^{\text {th }}$ years) with no previous expe- rience in laparoscopy were recruited from the University of Sao Paulo Medical School, and ten urology residents (PGY3-5) with limited laparoscopic experience were recruited from the University of Sao Paulo Medical School. Informed consent was obtained from every participant.

The training consisted of the execution of the following basic laparoscopic skills: camera navigation, cutting, peg transfer and clipping. For each skill, there were three levels of difficulty. During each training session, all tasks were performed at each level of difficulty. The length of the training was ten weeks, and each weekly session lasted approximately one to two hours. The number of sessions $(\mathrm{n}=10)$ was chosen based on the previous demonstration that a plateau in the learning curve occurs within 8 sessions of using the simulator (13). Each of the four tasks was performed three times during each session with increasing levels of difficulty (1 to 3). To insure uniformity, all participants were assisted by the same technician, who controlled the camera during the exercises except the camera navigation task.

The sessions were recorded, and an assessment of the performance was made by the simulator's software, which quantifies the time required to perform the task and the number of errors committed. Individual and group learning curves were obtained for each task and level of difficulty.

Analysis of variance (ANOVA) was performed with repeated measures of two factors, using the group as the fixed factor (Group I [students] $\mathrm{x}$ Group II [residents]) and the week as the repetition factor as well as assuming correlation matrices and unstructured and symmetric components between the weeks. For measures that showed statistically significant interactions between the groups and weeks, a comparison was made between the groups for each week. Contrasts were used to verify in which weeks the groups differed and in which weeks they began to be coincident. A 95\% confidence interval was established.

\section{RESULTS}

The average times (in seconds) and the standard deviations for the completion of each skill 
(difficulty levels 1 to 3 ) were obtained weekly for both groups. A portion of these data are represented in Table-1 (weeks 1, 5 and 10; level 2). As shown in this table, there was a reduction in the time task execution in both groups; this trend was not always followed by a similar variation in the standard deviation. In the first contact with the VRSS, the mean time to complete the tasks was in general (all three levels of difficulty) significantly different between the groups $(\mathrm{p}<0.05)$, with the residents performing up to 2 or 3 times faster than the students on average. The residents' group also completed the tasks with fewer errors in the first week.

When we analyzed the tasks and the levels of difficulty separately, a statistically significant difference - with residents completing the exercises in a shorter amount of time - was observed at the first level of difficulty only in the first week for all four tasks (all with $\mathrm{p}<0.05$ ). Residents performed the level 1 camera navigation task more quickly ( $p=0.02)$. At the second difficulty level, a significant $\mathrm{p}$-value for task completion time was obtained only in the first week for the clipping skill $(p=0.04)$, in the first two weeks for the peg transfer skill $(p=0.03)$ and up until week eight for the cutting skill $(\mathrm{p}=0.026)$. At the third level of difficulty, there was a significant difference in completion time between the groups up until week seven for both the clipping $(\mathrm{p}=0.01)$ and camera navigation $(p=0.029)$ tasks.

We analyzed the errors during the clipping and cutting skills, the number of dropped pegs in the peg transfer exercise, and the ability to focus on the target in camera navigation task. Group II (residents) performed statistically better than group I (students) in the first two weeks in the level 1 ability to find the target with the camera $(p=0.019)$. Similarly, group II performed better in the first week for the level two dropped pegs task $(\mathrm{p}=0.026)$. The most significant difference in the superior group II performance was observed for level three tasks: in the clipping skill in weeks

Table 1 - Average time (in seconds) for completion of the exercise and standard deviation. - Level 02.

\begin{tabular}{|c|c|c|c|c|}
\hline Skill & Week & Group I - Students & Group II - Residents & $P$ \\
\hline \multirow[t]{3}{*}{ Camera } & 1 & $427.6 \pm 97.67$ & $269.0 \pm 119.27$ & 0.004 \\
\hline & 5 & $388.4 \pm 155.03$ & $188.4 \pm 103.51$ & 0.002 \\
\hline & 10 & $205.0 \pm 115.77$ & $188.2 \pm 79.95$ & 0.737 \\
\hline \multirow[t]{3}{*}{ Clipping } & 1 & $149.5 \pm 48.72$ & $109.9 \pm 36.59$ & 0.043 \\
\hline & 5 & $100.3 \pm 36.48$ & $86.60 \pm 34.89$ & 0.377 \\
\hline & 10 & $69.55 \pm 20.82$ & $68.80 \pm 31.79$ & 0.833 \\
\hline \multirow[t]{3}{*}{ Cutting } & 1 & $413.8 \pm 132.8$ & $224.0 \pm 94.06$ & 0.001 \\
\hline & 5 & $240.4 \pm 83.73$ & $183.7 \pm 60.14$ & 0.026 \\
\hline & 10 & $156.5 \pm 32.09$ & $156.9 \pm 49.96$ & 0.353 \\
\hline \multirow[t]{3}{*}{ Peg Transfer } & 1 & $656.9 \pm 316.8$ & $339.1 \pm 72.69$ & 0.049 \\
\hline & 5 & $292.9 \pm 78.33$ & $263.6 \pm 100.7$ & 0.453 \\
\hline & 10 & $214.3 \pm 80.83$ & $203.2 \pm 65.43$ & 0.283 \\
\hline
\end{tabular}


one through six ( $\mathrm{p}=0.05)$; up until week seven in target locating with the camera $(p=0.026)$; and up through week eight in the number of errors in camera navigation $(p=0.048)$.

The majority of the medical students and residents exhibited a statistically significant improvement in task completion time and error rate between the first 5 and the last 5 training sessions. Comparing the final performance of both groups, we found no statistically significant difference in any of the four basic skills for all three levels of difficulty.

\section{DISCUSSION}

Although minimally invasive surgery has revolutionized surgical techniques, laparoscopic skill acquisition has proven to be a significant and technically difficult challenge, requiring a different 'skill set' than traditional open surgery as well as presenting differences in cost, safety and ethical issues (14). Among the technical aspects, learning laparoscopic skills demands three-dimensional interpretation of a two-dimensionally represented scenario and the manipulation of endoscopic instruments (15). In addition, laparoscopic surgery has the further challenges of reduced depth perception and attenuations in the tactile sensations and end-force of the instruments (16). Such factors produce the broader base and greater slope of the learning curve, which presents a challenge in the OR environment (17-20). In this sense, VRSS has emerged as an intriguing and promising tool, enabling apprentices to acquaint themselves with this novel reality, to practice basic skills and to practice specific procedures of minor complexity. This device offers convenient and unlimited practice with the advantages of low cost and the absence of ethical concerns (21). However, it is unclear whether the use of VRSS results in a quantifiable improvement in laparoscopic surgical skills.

Previous studies have demonstrated that VRSS is a useful tool to discriminate novices from experts $(22,23)$. In the present study, our general analysis was similarly able to distinguish medical students with no laparoscopic experience from residents with laparoscopic experience. In a deeper analysis, when we examined each basic skill se- parately at the three difficulty levels, the ability to discriminate between the two groups was not always present. A significant difference was observed at the first level of difficulty for all tasks but could not be observed for camera navigation at the second level or for cutting and peg transfer at the third difficulty level. When we assessed these differences throughout our training, we observed the trend that the performances gradually reached a plateau and became similar, so that by the end of the training, there was no significant difference between the groups. Our findings of the time to achieve plateau were consistent with previous studies, which shown that ten weeks is more than sufficient to ensure that a plateau in the learning curve was reached, even for beginners.

Learning is indirectly represented by the improvement in motor performance, which is inferred in terms of the speed and task precision in repetitive trials. In our study, we observed the skill learning in both groups through numerical and graphical displays (Figure-1 - learning curves of time on clipping skill, for all three levels). In support of these findings, previous studies have demonstrated that VRSS training results in a decrease in task conclusion time coupled with an increase in task execution accuracy for trainees without previous experience as well as for trainees with limited laparoscopic experience (24).

We recognize several limitations in this study. The number of participants used in our study may have been insufficient to demonstrate greater significant differences between the groups over the weeks of training. It is possible that increasing our sample size could empower the study and show larger differences in the trends found.

\section{CONCLUSIONS}

The many potential benefits of VRSS have prompted their emergence as optimal tools for training outside operating room. Our findings demonstrate that basic laparoscopic skills can be objectively measured using the skill parameters performed in a virtual reality surgical simulator by monitoring the time spent to perform the skill tasks and the associated error rate. VRSS has been shown to be a feasible tool for the training and 
Figure 1 - Learning curves of time on clipping skill, for all three levels.
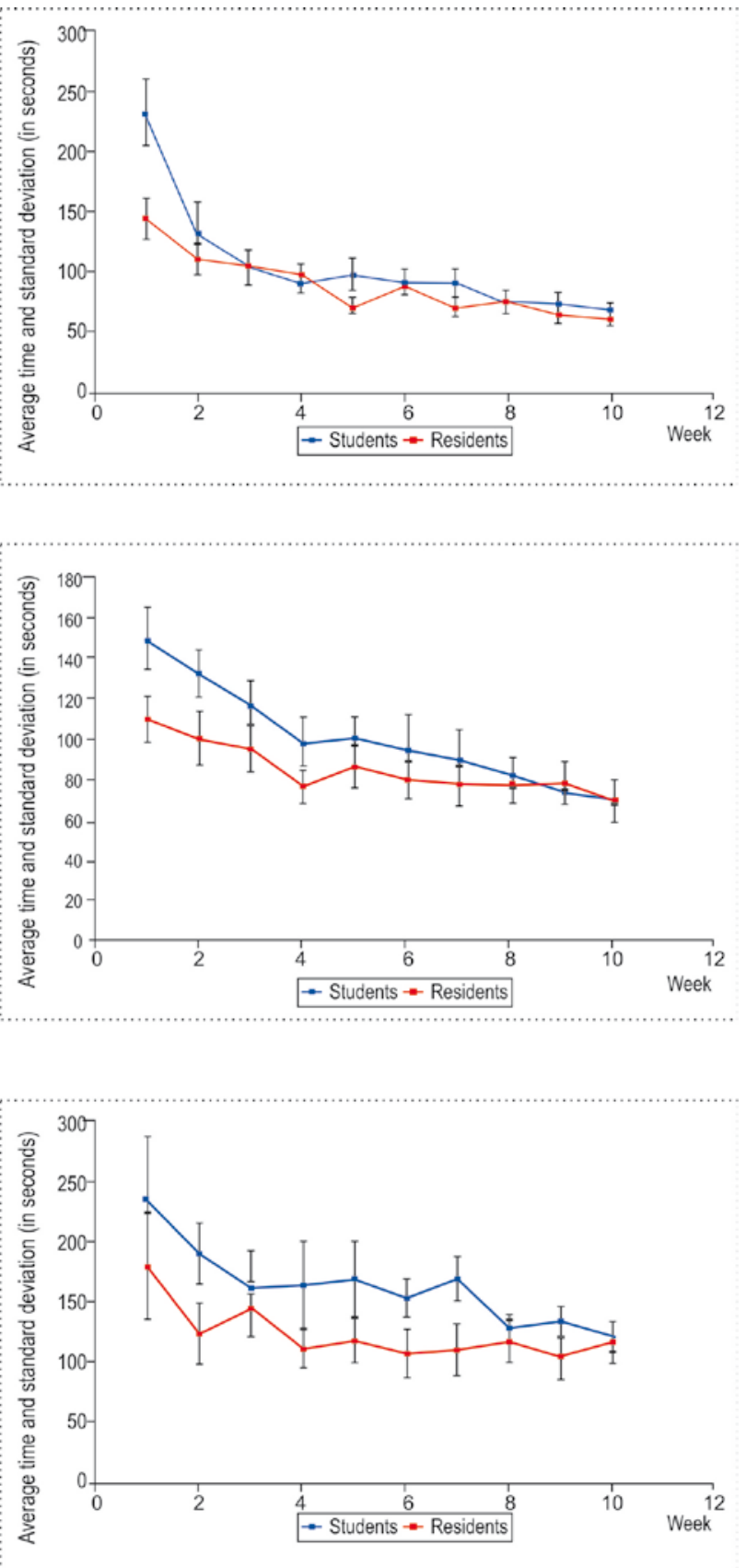

assessment of basic laparoscopic skills for trainees without previous laparoscopic experience as well as trainees with limited experience, with more gain for the former group. However, it remains unclear whether improvement in the skill tasks in VRSS can be directly translated into improvements in actual surgical performance.

\section{ACKNOWLEDGMENTS}

We would like to thank Marcelo Junqueira Atanázio, Marina de Paula Andres, Osmar Bianchi da Silva, Pedro Gomes Penteado Rosa, Renato Antunes Schiave Germano, Rogério Heggendorn Sayão Filho, Simon Benabou, Maurício Cordeiro and Rafael Coelho for taking the time to train on the VRSS. We also would like thank all of the support given by Débora Anselmo Juliano, Joselito da Silva Estrela, Adriana Sañudo, and Rogério Ruscitto do Prado.

\section{CONFLICT OF INTEREST}

None declared.

\section{REFERENCES}

1. Undre S, Darzi A: Laparoscopy simulators. J Endourol. 2007; 21: 274-9.

2. Grantcharov TP, Bardram L, Funch-Jensen P, Rosenberg J: Learning curves and impact of previous operative experience on performance on a virtual reality simulator to test laparoscopic surgical skills. Am J Surg. 2003; 185: 146-9.

3. Suzuki S, Eto K, Hattori A, Yanaga K, Suzuki N: Surgery simulation using patient-specific models for laparoscopic colectomy. Stud Health Technol Inform. 2007; 125: 464-6.

4. Olagundoye V, Adeghe J, Guirguis M, Cox C, Murphy D: Laparoscopic surgical management of ectopic pregnancy: a district general hospital experience. J Obstet Gynaecol. 2000; 20: 620-3.

5. Hanna GB, Shimi SM, Cuschieri A: Randomised study of influence of two-dimensional versus three-dimensional imaging on performance of laparoscopic cholecystectomy. Lancet. 1998; 351: 248-51.

6. Gallagher AG, McClure N, McGuigan J, Ritchie K, Sheehy NP: An ergonomic analysis of the fulcrum effect in the acquisition of endoscopic skills. Endoscopy. 1998; 30: 617-20.

7. Kuhry E, van Veen RN, Langeveld HR, Steyerberg EW, Jeekel $\mathrm{J}$, Bonjer $\mathrm{HJ}$ : Open or endoscopic total extraperitoneal inguinal hernia repair? A systematic review. Surg Endosc. 2007; 21: 161-6. 
8. Scott DJ, Bergen PC, Rege RV, Laycock R, Tesfay ST, Valentine RJ, et al.: Laparoscopic training on bench models: better and more cost effective than operating room experience? J Am Coll Surg. 2000; 191: 272-83.

9. Aggarwal R, Moorthy K, Darzi A: Laparoscopic skills training and assessment. Br J Surg. 2004; 91: 1549-58.

10. Satava RM: Accomplishments and challenges of surgical simulation. Surg Endosc. 2001; 15: 232-41.

11. Gallagher AG, Cates CU: Virtual reality training for the operating room and cardiac catheterisation laboratory. Lancet. 2004; 364: 1538-40.

12. Uranüs $S$, Yanik M, Bretthauer G: Virtual reality in laparoscopic surgery. Stud Health Technol Inform. 2004; 104:151-5.

13. Hogle NJ, Briggs WM, Fowler DL: Documenting a learning curve and test-retest reliability of two tasks on a virtual reality training simulator in laparoscopic surgery. J Surg Educ. 2007; 64: 424-30.

14. Woodrum DT, Andreatta PB, Yellamanchilli RK, Feryus L, Gauger PG, Minter RM: Construct validity of the LapSim laparoscopic surgical simulator. Am J Surg. 2006; 191: 2832.

15. Hanna GB, Cuschieri A: Influence of the optical axis-totarget view angle on endoscopic task performance. Surg Endosc. 1999; 13: 371-5.

16. Torkington J, Smith SG, Rees BI, Darzi A: The role of simulation in surgical training. Ann R Coll Surg Engl. 2000; 82 88-94.

17. Bais JE, Bartelsman JF, Bonjer HJ, Cuesta MA, Go PM, Klinkenberg-Knol EC, et al.: Laparoscopic or conventional Nissen fundoplication for gastro-oesophageal reflux disease: randomised clinical trial. The Netherlands Antireflux Surgery Study Group. Lancet. 2000; 355: 170-4.
18. Gouma DJ, Go PM: Bile duct injury during laparoscopic and conventional cholecystectomy. J Am Coll Surg. 1994; 178: 229-33.

19. Moore MJ, Bennett CL: The learning curve for laparoscopic cholecystectomy. The Southern Surgeons Club. Am J Surg. 1995; 170: 55-9.

20. Sariego J, Spitzer L, Matsumoto T: The "learning curve" in the performance of laparoscopic cholecystectomy. Int Surg. 1993; 78: 1-3.

21. da Cruz JA, Sandy NS, Passerotti CC, Nguyen H, Antunes AA, Dos Reis ST, et al.: Does training laparoscopic skills in a virtual reality simulator improve surgical performance? J Endourol. 2010; 24: 1845-9.

22. Maithel S, Sierra R, Korndorffer J, Neumann P, Dawson S, Callery M, et al.: Construct and face validity of MIST-VR, Endotower, and CELTS: are we ready for skills assessment using simulators? Surg Endosc. 2006; 20: 104-12.

23. van Dongen KW, Tournoij E, van der Zee DC, Schijven MP, Broeders IA: Construct validity of the LapSim: can the LapSim virtual reality simulator distinguish between novices and experts? Surg Endosc. 2007; 21: 1413-7.

24. Gurusamy K, Aggarwal R, Palanivelu L, Davidson BR: Systematic review of randomized controlled trials on the effectiveness of virtual reality training for laparoscopic surgery. Br J Surg. 2008; 95: 1088-97.

Correspondence address: Dr. Carlo C. Passerotti

Rua Barata Ribeiro, 490 / 76 Sao Paulo, SP, 01308-000, Brazil Fax: + 5511 3255-6372 E-mail: carlopasserotti@hotmail.com 